\title{
Using remote sensing to quantify albedo of roofs in seven California cities, Part 1: Methods
}

\author{
George A Ban-Weiss ${ }^{\mathrm{a}, \mathrm{b}^{*}}$, Jordan Woods ${ }^{\mathrm{b}}$, Ronnen Levinson ${ }^{\mathrm{b}}$ \\ ${ }^{a}$ Dept of Civil and Environmental Engineering \\ University of Southern California \\ 3620 Vermont Ave KAP210 \\ Los Angeles, CA 90089 \\ ${ }^{\mathrm{b}}$ Environmental Energy Technologies Division \\ Lawrence Berkeley National Laboratory \\ One Cyclotron Road \\ Berkeley, CA 94720
}

\footnotetext{
* Corresponding author:

George Ban-Weiss

Dept of Civil and Environmental Engineering

University of Southern California

3620 Vermont Ave KAP210

Los Angeles, CA 90089

banweiss@usc.edu

Phone +12137409124

Fax +1 213 744-1426
} 


\section{Abstract}

2 Cool roofs reflect sunlight and therefore can reduce cooling energy use in buildings.

3 Further, since roofs cover about $20-25 \%$ of most cities, widespread deployment of cool

4 roofs could mitigate the urban heat island effect and partially counter urban temperature

5 increases associated with global scale climate change. The magnitude of these potential

6 benefits for a given city depends on the increase in albedo that can be achieved using

7 reflective roofs. Assessing this increase requires knowledge of roof albedo at the city-

8 scale, which until now has been unknown due to a lack of reflectance data with sufficient

9 spatial coverage, spatial resolution, and spectral information. In this work we use

10 multiband aerial imagery to derive the albedos of individual roofs in seven California

11 cities: Los Angeles, Long Beach, San Diego, Bakersfield, Sacramento, San Francisco,

12 and San Jose. The radiometrically calibrated, remotely sensed imagery has high spatial

13 resolution (1 m) and four narrow band reflectances: blue, green, red, and near-infrared.

14 First, we locate roof pixels within GIS building outlines. Next, we use laboratory

15 measurements of the solar spectral reflectances of 190 roofing products to empirically

16 relate broadband solar reflectance to reflectances in the four narrow bands; the empirical

17 relationship well predicts solar reflectance as indicated by a low root-mean-square of the

18 residuals of 0.016 . Albedos computed from remotely sensed reflectances are calibrated to

19 ground measurements of roof albedo in each city. The error (accuracy) at 90\% confidence

20 interval of the calibrated albedos is found to vary by city from $0.00-0.01$ at low albedo

21 and $0.06-0.14$ at high albedo.

22 Keywords: albedo; solar reflectance; cool roof; heat island effect 


\section{1. Introduction}

24 Roofs cover the top of buildings, separating the atmosphere and the indoor environment.

25 The solar reflectance or "albedo" of a rooftop is the fraction of incident solar energy that

26 is reflected. Sunlight that is not reflected is instead absorbed by the roof; this energy is

27 then transferred to the interior of the building and to the atmosphere. Dark roofs can have

28 albedos as low as 0.05 , meaning that they can absorb up to $95 \%$ of incident sunlight.

29 Clean bright white roofs can have albedos above 0.90 (CRRC 2013), reflecting nearly all

30 incident sunlight.

31 Monitoring studies have shown that replacing a dark roof with a white roof can decrease

32 heat flows into the conditioned space, and lower cooling energy use. In many cases,

33 cooling energy use reductions of $10-20 \%$ have been observed (Parker et al. 1995;

34 Akbari et al. 1997; Parker et al. 1998; Akbari et al. 2001; Konopacki and Akbari 2001;

35 Akbari 2003; Akbari et al. 2005). The cooling energy savings attainable for a particular

36 building depends on its construction, roof and attic insulation, shade cover, and climate.

37 In some situations, such as when roofs are thermally decoupled from the conditioned

38 space, reflective roofs can have negligible effect on energy use (Ban-Weiss et al. 2013).

39 Recognizing the potential energy and cost savings of white roofs, in October 2005 the

40 California Energy Commission added to its Title 24 Building Energy Efficiency

41 Standards (CEC 2005) a prescription that new or retrofitted low-sloped roofs on

42 commercial buildings should generally be white. When the costs of white and dark roofs

43 are approximately the same, reductions in energy costs translate directly to money saved.

44 Note that while reflective roofs can increase heating energy use requirements in the 
45 winter, summer cooling cost savings in most of California's climate zones far outweigh

46 this winter heating cost penalty (Levinson and Akbari 2010).

47 Solar reflective roofs have lower surface temperatures and thus transfer less heat to the

48 atmosphere than dark roofs. In most cases this reduced heat flow lowers surrounding air

49 temperatures. An observational study (Campra et al. 2008) showed that from 1983 -

502006 , a region of southeastern Spain experienced near-surface air temperature decreases

51 of about $0.3{ }^{\circ} \mathrm{C} /$ decade as greenhouses with high albedo roofs were deployed. Since

52 roofs on average comprise about $20-25 \%$ of surface areas in North American cities

53 (Akbari et al. 1999; Akbari and Rose 2001a; Akbari and Rose 2001b; Akbari et al. 2003;

54 Rose et al. 2003; Akbari and Rose 2008), large-scale deployment of white roofs has been

55 suggested as a measure to mitigate the urban heat island effect (Taha et al. 1998; Akbari

56 et al. 1990; Akbari et al. 1992; Rosenfeld et al. 1995). Similarly, reflective roofs may

57 lessen urban temperature increases associated with global scale climate change. A remote

58 sensing study (Mackey et al. 2012) found that use of cool roofs in Chicago for reducing

59 urban heat islands has increased city-wide albedo and decreased roof surface

60 temperatures as detected by the LANDSAT satellite. Various mesoscale climate

61 modeling studies have simulated the climate effects of hypothetical increases in urban

62 albedo. For example, simulations reported by Taha (2008a) found $1-2{ }^{\circ} \mathrm{C}$ decreases in

63 peak urban temperatures at six locations in California. Other studies have shown

64 comparable temperature reductions in other regions (Synnefa et al. 2008; Taha 2008b;

65 Lynn et al. 2009; Zhou and Shepherd 2009). We note that one study showed that in some

66 situations urban air temperatures can rise with increased urban albedo (Taha 2008c); this 
67 study hypothesized that the modeled temperature increase in Houston, Texas was due to

68 reduction of the atmospheric mixing height.

69 Other modeling studies have investigated the effect of increasing urban albedo across the

70 United States (Millstein and Menon 2011) and globally (Akbari et al. 2009; Menon et al.

71 2010; Oleson et al. 2010; Jacobson and Ten Hoeve 2012; Akbari and Matthews 2012;

72 Akbari et al. 2012; Cotana et al. 2014). Millstein and Menon (2011) used a regional

73 climate model to show that adopting cool roofs and pavements in urban areas of the

74 United States could reduce afternoon summertime temperatures in urban locations by 0.1

$75-0.5^{\circ} \mathrm{C}$. A study using a global climate model (Oleson et al. 2010) demonstrated that

76 reflective surfaces could decrease the annual mean urban heat island effect ${ }^{1}$ to $0.8{ }^{\circ} \mathrm{C}$

77 from $1.2{ }^{\circ} \mathrm{C}$.

78 While reflective surfaces have been modeled in most situations to reduce urban

79 temperatures, their effects on the hydrological cycle also warrants investigation. One

80 mesoscale climate modeling study (Georgescu et al. 2012) has suggested that reflective

81 surfaces may reduce precipitation around Phoenix, Arizona. Since Phoenix has unique

82 desert meteorology with most of its precipitation arriving with late-summer monsoon

83 thunderstorms, this result may not hold in other regions.

84 Determining realistic estimates of the potential for increasing roof albedo at the city scale

85 requires detailed understanding of the current stock of roofs. Currently there are no

86 estimates of the mean urban roof albedos. There are at least five challenges associated

87 with quantifying roof albedo at the city scale: spatial coverage, spatial resolution, spectral

\footnotetext{
${ }^{1}$ The urban heat island effect was defined by Oleson et al. (2010) as the difference (urban - non-urban) in 2-m air temperature between urban and non-urban portions of model grid cells.
} 
88 coverage, radiometric calibration, and cost. For example, roof albedo can be accurately

89 measured at the rooftop by using a pyranometer to measure incident and reflected

90 (bihemispherical) sunlight (ASTM 2006). However, measuring a sample large enough to

91 statistically represent the roofs of a city is logistically prohibitive. Remote sensing can

92 rapidly characterize large geographic areas. For example, there exist freely available

93 surface albedo datasets derived from satellite sensors like MODIS (Schaaf et al. 2002;

94 Schaaf 2004). Data are available describing both directional-hemispherical reflectance

95 (referred to as "black-sky" albedo) and bihemispherical reflectance (referred to as white-

96 sky albedo). However, its spatial resolution of $500 \mathrm{~m}$ (16-day composites) is too low to

97 distinguish various urban surface types such as roofs. Imagery from commercial satellites

98 (e.g., GeoEye, IKONOS) offers spatial resolutions on the order of $1 \mathrm{~m}$ and spectral

99 information in the visible and near-infrared (near-IR). While the spatial resolution and

100 spectral coverage may be sufficient to distinguish roofs and compute roof albedo,

101 purchasing these imagery for entire cities would be costly. As of 2014, minimum costs

102 for these data are roughly US\$15 per $\mathrm{km}^{2}$, so acquiring imagery for only the City of Los

103 Angeles would be about \$20,000, and for the entire metropolitan area of Los Angeles

104 about $\$ 200,000$. Another option is aerial imagery, which is often acquired from aircraft.

105 Since these aircraft are generally nearer to the ground than satellites, the captured

106 imagery is at higher spatial resolution. While aerial imagery can sometimes provide

107 multiband information in the visible and near-IR, it is almost always acquired for

108 generating photographs and therefore does not provide the calibrated radiance data

109 needed for scientific analysis. To overcome the aforementioned challenges associated

110 with spatial coverage of ground measurements, cost and spatial resolution of satellite 
111 data, and radiometric limitations of most aerial imagery, we acquired high-resolution,

112 radiometrically calibrated, aerial imagery for the purpose of deriving roof albedos.

113 In this paper we develop a method for using radiometrically calibrated aerial imagery to

114 estimate roof albedos for seven cities in California: Los Angeles, Long Beach, San

115 Diego, Bakersfield, Sacramento, San Francisco, and San Jose. The aerial imagery has

116 high spatial resolution $(1 \mathrm{~m})$ and includes reflectances in four narrow spectral bands:

117 three in the visible (blue, green, and red), and one in the near-infrared. The near-IR

118 contains approximately $50 \%$ of the energy from the sun (Levinson et al. 2010). Some

119 "cool roofs" have low reflectance in the visible spectrum but high reflectance in the near-

120 IR spectrum, allowing the roof to remain dark while increasing its albedo (Levinson et al.

121 2007). Thus, having information about reflectance in both the visible and near-IR spectra

122 improves estimates of roof albedo. The work is presented in two parts. In Part 1 (this

123 paper), we present methods for calculating roof albedo from remotely sensed

124 reflectances, and show sample results. Part 2 (a companion paper, Ban-Weiss et al.

125 submitted) reports roof albedos in each of the seven California cities of interest. It also

126 provides further analyses and applications using the albedo dataset. Applications include

127 use of roof albedos in a regional climate model to estimate temperature decreases

128 attainable by converting the current stock of roofs to solar reflective cool roofs. This

129 work is a first attempt to quantify the albedos of individual roofs at the scale of entire

130 cities.

\section{2. Methods}

132 In this section we describe the methods developed to derive the albedos of roofs in seven

133 California cities: Los Angeles, Long Beach, San Diego, Bakersfield, Sacramento, San 
134 Francisco, and San Jose. Figure 1 diagrams the approach. Reflectances in narrow bands

135 denoted blue, green, red, and near-IR were obtained from high spatial resolution (1 m)

136 imagery acquired using airplanes during summer 2009. We refer to the data collected

137 using the airplane as "remotely sensed." Pixels containing roofs were then extracted from

138 the imagery. Roof pixels were identified using GIS building outline datasets for entire

139 cities where available. When building outline datasets were not available, manual tracing

140 of buildings was performed. Laboratory measurements of the solar spectral reflectances

141 of 190 roofing products were used to empirically relate solar reflectance to reflectances in

142 the four narrow bands. Remotely sensed solar reflectances were calibrated to ground

143 measurements of roof albedo in each city. Pixels within each roof boundary were then

144 averaged to calculate the mean albedo of each roof. Note that we define albedo

145 consistently with the "cool roof" scientific community as the ratio of reflected to incident

146 broadband solar radiation, and subsequently specify the illumination-viewing geometry

147 for each measurement. Each step is now described in more detail.

\section{2.1. Data source}

149 The aerial imagery was originally acquired for the National Agriculture Imagery Program

150 (NAIP), which is administered by the US Department of Agriculture (USDA). NAIP

151 annually acquires aerial imagery during the agricultural growing season (late spring to

152 early summer) in the continental United States. One of the main goals of NAIP is to

153 provide digital ortho photography to government agencies and the public. While this

154 program is focused on agriculture, imagery is generally acquired for entire states

155 including urban areas. NAIP has strict requirements to ensure high image quality. For

156 example, to minimize shadows, flights must occur when the sun is at least 30 degrees 
157 above the horizon. In practice, all imagery is collected when the sun is at least 60 degrees

158 above the horizon. Flights must acquire imagery on clear days without cloud cover

159 (NAIP 2013).

160 NAIP imagery is available for the entire state of California at $1 \mathrm{~m}$ spatial resolution in

161 years 2005, 2009, 2010, and 2012 (NAIP 2013). NAIP contracts different companies to

162 acquire imagery each year. As such, various imagery acquisition systems have been used.

163 In 2009, imagery for California was collected by North West Group (Calgary, Alberta,

164 Canada) using a Leica ADS80/SH82 airborne digital sensor (Leica 2013). This sensor is

165 more than a high-speed digital camera for photography. It utilizes arrays of digital

166 charge-coupled devices that sense light in four narrow spectral bands (blue, 420 - 492

$167 \mathrm{~nm}$; green, $533-587 \mathrm{~nm}$; red, $604-664 \mathrm{~nm}$; and near-IR, $833-920 \mathrm{~nm}$ ). The arrays of

168 detectors are arranged perpendicular to the flight direction in a "push broom"

169 configuration. Each detector is radiometrically calibrated in the laboratory to accurately

170 measure radiance in its spectral band. Thus, the sensor accurately measures multi-spectral

171 radiance, similar to that acquired by sensors on satellites for scientific applications. In

172 this way, the imagery collected by the sensor has the potential to be used as a scientific

173 remote sensing data set, rather than simply as photographs. NAIP imagery is publically

174 available as either "digital ortho quarter quad tiles" (DOQQs) or "compressed county

175 mosaics" (CCM); both options include imagery compression, a variety of color

176 adjustments, and other post-processing required by NAIP (NAIP 2013). This post-

177 processing improves the overall appearance and usability of the imagery, but destroys the

178 radiometric calibration, which is important for the purposes of this study. Therefore, we

179 acquired directly from NAIP's vendor for 2009 (North West Group) the radiometrically 
180 calibrated radiance data for images within our cities of interest. The field of view of the

181 sensor resulted in image footprints that are $12 \mathrm{~km}$ wide (perpendicular to flight direction),

182 and of varying length depending on flight paths. The mean altitude of the flights was

183 about $9 \mathrm{~km}$ above ground level, leading to view zenith angles for the line scanner up to

184 about $34^{\circ}$. Each flight strip has $15 \%$ overlap with the adjacent flight strip corresponding

185 to view zenith angles of $30^{\circ}$ to $34^{\circ}$; thus, about $30 \%$ of the area for each city has

186 duplicate imagery.

187 2.2. Correcting for the atmosphere and surface reflectance anisotropy

188 Since we are interested in reflectance at Earth's surface, the radiance measurements at the

189 sensor (on the airplane) needed to be corrected for atmospheric scattering and for surface

190 reflectance anisotropy. Techniques have been previously developed and described at

191 length elsewhere, so we provide only a brief description here.

192 Atmospheric gases and particles can influence the perceived "at-sensor" radiance through

193 multiple pathways (Schaepman-Strub et al. 2006; Downey et al. 2010). The atmospheric

194 correction allows for estimating surface reflectance by isolating (a) the radiance that

195 originates from the Earth surface, and (b) the solar spectral irradiance at the surface. The

196 surface spectral reflectance, a characteristic of the coupled surface-atmosphere system, is

197 a function of the measured at-sensor radiance, the mean solar spectral irradiance at the

198 top of atmosphere (TOA), the path radiance over an absorbing surface (i.e., the "dark

199 pixel" radiance from downwelling sunlight that is reflected by the atmosphere into the

200 sensor before having reached the surface), the total downward transmittance from the

201 TOA to the ground, the total upward transmittance from the ground to the sensor, and the

202 spherical albedo of the atmosphere (i.e., the fraction of upward radiance that is then 
203 backscattered by the atmosphere) (Kaufman and Sendra 1988, Fraser et al. 1992). The

204 first term, at-sensor radiance, is measured. The second term, TOA mean solar spectral

205 irradiance, can be computed from the solar constant as a function of the cosine of the

206 solar zenith angle. The latter four unknown terms are estimated using a modified Song-

207 Lu-Wesley method (Song et al., 2003, Downey et al. 2000), which is based on a linear

208 parameterization similar to that used by the Advanced Very High Resolution Radiometer

209 (AVHRR) satellite sensor. The atmospheric reflectance for each view and sun zenith

210 angle is first estimated using expected versus measured surface reflectances for dark

211 pixels. The four unknown parameters are then determined for each spectral band based on

212 parameterizations derived from atmospheric modeling performed for various flying

213 heights, ground elevations, sun and view zenith angles, and atmospheric reflectances.

214 Past studies have validated the atmospheric correction by comparing to ground

215 reflectance measurements (Beisl and Adiguezel 2010; Markelin et al. 2010) and found

216 agreement to within $10 \%$.

217 The correction accounting for surface reflectance anisotropy is based on a modified

218 Walthall method (Beisl et al. 2008, Downey et al. 2010). Since flights for NAIP are

219 always in the north-south direction, the correction minimizes spurious east-west gradients

220 in reflectance (i.e., perpendicular to the flight direction). The method is semi-empirical

221 and the sum of "kernals" accounting for incident illumination zenith angle, reflection

222 view zenith angle, relative azimuth angle (Nilson and Kuusk, 1989), and an additional

223 "hot spot" term based on the distance function of the Li-kernals from the AMBRALS

224 model (Wanner et al. 1995). The correction in part uses summary statistics for land pixels 
225 at equal viewing zenith angles and masks water so that specular reflection does not

226 influence results (Downey et al. 2010).

227 Strictly speaking, the resulting reflectances described here are hemisphere-directional

228 reflectance factors (HDRF), using the naming conventions described by Schaepman-

229 Strub et al. (2006). In this investigation we aim to derive bihemispherical reflectances

230 (BHR). The most physical methods for deriving BHR from HDRF require either

231 knowledge of the Bidirectional Reflectance Distribution Function (BRDF) for each

232 roofing material, or many aerial images for each location at a variety of viewing angles.

233 Because we have neither, we use rooftop measurements of BHR to 'calibrate' HDRFs

234 (see Section 2.5). Such a calibration is justified by the high correlation observed between

235 HDRF and BHR for vegetation canopies, shown in Figure 4 of Schaepman-Strub et al.

236 (2006); we expect even higher correlation for roofing materials given that their surfaces

237 are generally more isotropic than natural vegetative surfaces. While this simplification

238 contributes to the errors later discussed in Section 3.2 and reported in Table 3, we note

239 that differences between HDRF and BHR are generally small. For example, for

240 vegetation canopies, the absolute difference between these two metrics is $<0.02$, with

241 relative differences up to $14 \%$, which is tolerable for the purposes of our study

242 (Schaepman-Strub et al. 2006). Because of the reduced anisotropy of roofs, differences

243 are expected to be lower for roofs than vegetation. Errors introduced by this

244 simplification are explored in Section 4.2, which compares albedos for buildings with

245 duplicate values computed independently using two different view zenith angles (about

$246 \square 30^{\circ}$ versus $\left.+30^{\circ}\right)$. 
247 Surface reflectances (HDRFs) are reported for each of the four narrow bands in each $1 \mathrm{~m}$

248 pixel; we refer to these as the remotely sensed blue, green, red, and near-infrared

249 reflectances. Figure 2 shows example imagery for the four narrow bands in a portion of

250 San Jose, California. Low reflectance pixels in each narrow band are dark, and high

251 reflectance pixels are white. (Note that the line of trees on the right side of the image

252 shows higher reflectance in near-IR than in the red, a characteristic of light reflection

253 from leafs (Slatton et al. 2001).) The remainder of the method sections describe our

254 derivation of roof albedo (i.e. broadband solar reflectance) from these narrowband

255 reflectances (Figure 2).

\subsection{Extracting roof pixels from the imagery}

257 Next we identify in the imagery pixels containing roofs. For five of the seven cities of

258 interest (Los Angeles, Long Beach, Bakersfield, San Francisco, and San Jose), shapefiles

259 containing outlines for every building within the city were acquired from local

260 governments (Table 1). Example building outlines projected onto a red-green-blue (RGB)

261 composite of the aerial imagery in San Jose are shown in Figure 3a. The building outlines

262 include detailed features of each building, as can be better observed when projected onto

263 higher spatial resolution (but not radiometrically calibrated) imagery from United States

264 Geological Survey (USGS) (Figure 3b). In our analysis we assume that building outlines

265 and roof outlines are colocated.

266 In the two cities for which we could not acquire building outlines (Sacramento and San

267 Diego), we manually traced the edges of buildings in the imagery using ESRI ArcMap

268 10.0. Manually tracing perfect outlines proved difficult. We therefore intentionally

269 traced outlines that were slightly within the actual building borders, ensuring that non- 
270 roof pixels were not included within the boundaries. Manually tracing every building was

271 not feasible, so we traced a small but statistically representative sample of buildings

272 within each of these two cities. To determine the number of buildings needed to properly

273 characterize the mean roof albedo of a city, we performed a Monte Carlo statistical

274 investigation using the population of albedo values computed for Los Angeles. As shown

275 in our companion paper (Ban-Weiss et al. submitted), 1000 roof outlines was found to be

276 sufficient. Hundreds of $300 \times 300 \mathrm{~m}^{2}$ quadrats (small, typically rectangular study regions)

277 were generated in random locations within city boundaries; all roofs within the borders of

278 the quadrats were traced until the minimum number of outlines $(N=1000)$ was met. An

279 example of manually traced outlines within a quadrat in Sacramento is shown in Figure

$2803 c$.

281 2.4. Relating broadband solar reflectance (albedo) to narrowband reflectances

282 To quantify the albedo of individual roofs, we need a method to relate broadband solar

283 reflectance to the four (narrowband) remotely sensed reflectances. In this section we

284 describe this spectral conversion. We note again that we use "albedo" to mean broadband

285 solar reflectance without regard to the angular characteristics of incoming and reflected

286 light; these geometries are instead described for each measurement. (This naming

287 convention is consistent with that of the cool roof scientific community, but is

288 inconsistent with that of the remote sensing community, which reserves albedo to mean

289 bihemispherical reflectance (Schaepman-Strub et al. 2006).) We began by computing the

290 solar, visible, and narrowband (blue, green, red, and near-IR) reflectances of each of 190

291 roofing products from laboratory measurements of solar spectral reflectance. Included in

292 the 190 samples were all widely used roofing types in California for both commercial and 
293 residential buildings (Table 2). Samples were new and mostly acquired from various

294 roofing supply stores in the San Francisco Bay area. Clay tile samples were provided by

295 MCA Superior Clay Roofing Tiles. While use of roofing materials that had been aged

296 outdoors was desired, it was infeasible to collect soiled roofing materials. Solar spectral

297 reflectance was measured using a PerkinElmer Lambda 900 UV/Vis/NIR

298 spectrophotometer equipped with a 150-mm Labsphere integrating sphere. Spectral

299 reflectances were measured from 300 to $2500 \mathrm{~nm}$ in $5 \mathrm{~nm}$ steps. All measurement are of

300 near-normal $\left(8^{\circ}\right)$ beam-hemispherical reflectance (a.k.a. directional-hemispherical

301 reflectance using the naming convention of Schaepman-Strub et al.) following ASTM

302 Standard E903-12.

303 Figure 4 shows the solar spectral reflectance, $\rho(\lambda)$, of several roofing products, as well

304 as the solar spectral irradiance, $j(\lambda)$, used to compute band reflectances. This air mass

305 one global horizontal (AM1GH) terrestrial irradiance assumes a clear sky and the sun at

306 zenith, and is suited to characterizing roof solar reflectance (Levinson et al. 2010).

307 Irradiance-weighted band reflectance $R$ over each range of interest was calculated as

$$
R=\frac{\int_{\text {range }} j(\lambda) \rho(\lambda) d \lambda}{\int_{\text {range }} j(\lambda) d \lambda} .
$$

308 We computed four narrowband reflectances—blue, $b(420-492 \mathrm{~nm})$; green, $g(533-$

$309587 \mathrm{~nm})$; red, $r(604-664 \mathrm{~nm})$; and near-IR, $i(833-920 \mathrm{~nm})$ - and three broadband

310 reflectances: visible, $V(400-700 \mathrm{~nm})$, near-IR, $I(700-2500 \mathrm{~nm})$, and solar, $S(300-$

$3112500 \mathrm{~nm}$ ). (Narrowband spectral ranges correspond to those of the remote sensor. 
312 Lowercase symbols represent narrowband reflectances and uppercase symbols represent

313 broadband reflectances.) Note that while the narrow blue, green, and red spectra

314 collectively span most of the visible spectrum, the narrow near-infrared spectrum used to

315 compute $i$ spans less than 5\% of the full near-infrared spectrum $(700-2500 \mathrm{~nm})$ (Figure

316 4). Hence, we expect $(b, g, r)$ to predict $V$ more accurately than $(b, g, r, i)$ can predict $317 S$.

318 Using the aforementioned laboratory measurements we developed empirical relationships

319 between broadband and narrowband reflectances using multivariate regression. We first

320 modeled $V=V(b, g, r)$ to test the method, then modeled $S=S(b, g, r, i)$.

\section{2.5. Calibrating remotely sensed values using ground truths}

322 To calibrate the remotely sensed values, we measured the albedos of several roofs in each

323 city, and then evaluated $S(b, g, r, i)$ for these roofs using remotely sensed $b, g, r$, and $i$.

324 Measured albedos were obtained using one of two methods. In the first, we identified

325 buildings that had new roofs installed within six months prior to the flights. The make

326 and model of the new roof was known, allowing us to obtain its albedo from an online

327 database (CRRC 2013). In the second, we measured rooftop albedos with a pyranometer.

328 The pyranometer measurements were performed in July 2012 in San Jose and Los

329 Angeles, and in September 2012 in San Francisco and Davis (near Sacramento). Since

330 these measurements were taken about three years after the imagery was acquired via

331 airplane, the second method was implemented only for roofs with low measured albedos (

$332 S<0.4$ ); as shown in Sleiman et al. (2011), aging (i.e., weathering and soiling) had a

333 small effect on the albedo of such roofs in this range. White roofing products can show 
334 marked decreases in albedo after three years (Sleiman et al. 2011) and were therefore not

335 included in this second method.

336 Method 1 (applied to all roofs). Several roof manufacturers and vendors identified the

337 make and model of roofs installed in each city no more than six months prior to each

338 flight. The initial solar reflectance of each installed roof was then obtained from the

339 Rated Products Directory of the Cool Roof Rating Council (CRRC 2013). Corresponding

340 remotely sensed albedos were then quantified by randomly sampling 10 pixels within the

341 roof boundary. Only pixels with visible roofing material were included; HVAC

342 equipment, solar photovoltaics, skylights, and other features were excluded. In total, 31

343 buildings with known installation dates and roofing product types were used.

344 Method 2 (applied only to roofs with low measured albedo). We measured the albedo of

345 roofs on 10 buildings in (or very near) four of the seven cities with a Kipp \& Zonen

346 CMA6 first-class albedometer, which integrates back-to-back a pair of Kipp \& Zonen

347 CMP6 first-class pyranometers. In situ roof albedos were measured following ASTM

348 Standard E1918-06, "Standard Test Method for Measuring the Solar Reflectance of

349 Horizontal and Low-Sloped Surfaces in the Field" (ASTM 2006), which determines

350 bihemispherical solar reflectance with solar beam incidence angle $<45^{\circ}$. Three

351 consecutive albedo measurements were performed at each of three locations on each roof,

352 for a total of nine measurements per roof. The mean albedo was calculated by averaging

353 these nine measurements. Corresponding remotely sensed albedos were extracted by

354 identifying each measurement location in the imagery; the mean value of pixels within a

$3553 \mathrm{~m}$ radius was calculated to approximate the field of view of the pyranometer. This was

356 done for each of the three measurement locations per roof. The three resulting albedos 
357 were then averaged and compared to the measurement-derived mean albedo for each

358 roof.

359 We were unable to obtain measurements for low albedo roofs in Bakersfield using either

360 Method 1 or 2. Instead, we obtained from Bakersfield Public Works records of asphalt

361 concrete pavement installations. Two roads were paved within one year prior to the

362 flights; installations were 3 weeks and 8 months prior to the flights, respectively.

363 Associated albedos were assumed to be 0.05 and 0.07 , respectively, derived from

364 measurements of the post-installation time evolution of asphalt pavement albedo

365 (unpublished). Corresponding remotely sensed values were obtained using the random

366 sampling technique described above for Method 1.

367 Measured albedo, $S_{\text {measured }}$, was regressed to remotely sensed albedo, $S(b, g, r, i)$, using a

368 power law relationship of the form

$$
S_{\text {measured }}=a_{c} S^{p_{c}}
$$

369 This was done separately for each city to determine parameters $a_{c}$ and $p_{c}$, where

370 subscript $c$ indexes the seven cities. These power law parameters were then used to

371 determine the calibrated remotely sensed (pixel level) albedo $S^{\prime}$ in each city as

$$
S^{\prime}=a_{c} S^{p_{c}}
$$

372 where the prime indicates "calibrated." The error $\varepsilon$ (accuracy) of the remotely sensed

373 albedos $\left(S^{\prime}\right)$ in each city was then estimated using the standard errors of the power law

374 parameters. Upper and lower-bound estimates of the coefficients were derived as mean 
375 value $\pm 90 \%$ confidence interval. One-sided confidence intervals above $\left(\varepsilon^{\cup}\right)$ and below

$376\left(\varepsilon^{\mathrm{L}}\right)$ the mean were then calculated as a function of calibrated albedo as

$$
\begin{gathered}
\mathcal{E}^{\mathrm{U}}\left(S^{\prime}\right)=a_{c}^{\mathrm{U}} S^{p_{c}^{\mathrm{U}}}-S^{\prime} \\
\mathcal{E}^{\mathrm{L}}\left(S^{\prime}\right)=S^{\prime}-a_{c}^{\mathrm{L}} S^{p_{c}^{\mathrm{L}}}
\end{gathered}
$$

377 where superscripts $\mathrm{U}$ and L correspond to upper- and lower-bound parameter estimates.

378 These error estimates indicate the accuracy with which calibrated albedos are calculated

379 from uncalibrated remotely sensed values. Note that we present one-sided confidence

380 intervals because the power law form of Eq. (3) makes $\varepsilon$ asymmetric about $S^{\prime}$.

381 White roofs are commonly single-ply (plastic) membranes or elastomeric coatings, both

382 of which are very smooth and glossy when new. Reflection from these materials can

383 therefore include a non-negligible specular component at high angles of sunlight

384 incidence (e.g., see Levinson et al. 2010). Since white roofs are almost always low-slope

385 and flights occurred with the sun at least $60^{\circ}$ above the horizon, we expect in most cases

386 that the specular component of reflection will be negligible. However, some commercial

387 roofs can be "wavy" and have areas with high pitch, making the incidence angle large

388 and introducing a non-negligible specular reflection. Such instances were seen in the

389 remotely sensed data as widely varying pixel-level roof albedos within the boundaries of

390 a roof, and were more likely to occur near the edges of flight strips. To ensure that roofs

391 used for calibration had negligible specular reflection reaching the aerial sensor, we

392 omitted buildings that (a) were near the flight strip edges, and (b) contained pixel-level

393 albedos within the roof boundary that varied by more than 0.1 . 
395 Mean albedos for each roof were calculated by averaging $S^{\prime}$ within each building

396 outline. Some non-roofing materials were included since roofs can house HVAC

397 equipment, skylights, solar photovoltaics, and other features. While we expect such

398 equipment to minimally affect the mean roof albedo for each city, it can strongly affect

399 the albedo of individual roofs. To estimate the magnitude of this effect, we used high-

400 resolution imagery from USGS (see Section 2.3 and Figure $3 b$ ) to compute the fraction of

401 roof area covered by non-roof elements for 150 randomly selected buildings in Los

402 Angeles. On average, non-roof elements were found to cover $2 \%$ of the footprint area for

403 these roofs. Buildings with low-slope roofs in many cases had a higher fractional

404 coverage by non-roof elements, but these buildings make up a relatively small fraction of

405 the total population of buildings in a city (see Ban-Weiss et al. submitted).

\section{2.7. Precision of the remotely sensed albedos}

407 As was mentioned in Section 2.1, about $30 \%$ of each city has overlapping imagery and

408 therefore two values of remotely sensed roof albedo. For each city, duplicates were used

409 to determine the precision error calculated as the scaled arithmetic difference,

$$
\text { Scaled arithmetic difference }=\frac{\left(S_{2}^{\prime}-S_{1}^{\prime}\right)}{\sqrt{2}}
$$

410 where subscripts 1 and 2 describe each duplicate value. Note that there is imprecision in

411 each value $S_{1}^{\prime}$ and $S_{2}^{\prime}$; since these imprecisions add quadratically, we divide by $\sqrt{2}$ in

412 Eq. (6) to determine the precision of one measurement (Hyslop and White 2009). Each of 
413 the duplicates compares albedo computed using data obtained at two different view

414 zenith angles ( $\square 34^{\circ}$ to $\square 30^{\circ}$ versus $+30^{\circ}$ to $+34^{\circ}$ ) and solar zenith angles (see Section 415 2.1).

\section{3. Results}

417 3.1. Obtaining solar reflectance (broadband) from remotely sensed (narrowband) 418 reflectances

419 We modeled $V=V(b, g, r)$ using the simple linear form

$$
V_{k}=c_{\mathrm{b}} b_{k}+c_{\mathrm{g}} g_{k}+c_{\mathrm{r}} r_{k}
$$

420 Here $V_{k}, b_{k}, g_{k}$, and $r_{k}$ are band reflectances computed from Eq. (1); each $c$ is a fitted

421 coefficient; and subscript $k$ indexes the 190 roofing samples. This linear model with $422 c_{\mathrm{b}}=0.37, c_{\mathrm{g}}=0.30$, and $c_{\mathrm{r}}=0.31$ predicts $V$ with a coefficient of determination $\mathrm{R}^{2}=$

423 0.99. Figure 5a evaluates the empirical model by comparing $V\left(b_{k}, g_{k}, r_{k}\right)$ to $V_{k}$. The

424 minimal deviation of points from the one-to-one line indicates that the linear model well 425 predicts $V$. A histogram of residuals (Figure 5b) shows that the linear model can predict

$426 \quad V$ to within 0.02 ; the root mean square (RMS) error $\chi$ is 0.003 . Adding higher order

427 terms and/or cross products to Eq. (7) did not improve the fit.

428 Next we attempted to quantify solar reflectance as

$$
S_{k}=c_{\mathrm{b}} b_{k}+c_{\mathrm{g}} g_{k}+c_{\mathrm{r}} r_{k}+c_{\mathrm{i}} i_{k}
$$

429 The linear model with $c_{\mathrm{b}}=0.17, c_{\mathrm{g}}=-0.13, c_{\mathrm{r}}=0.33$, and $c_{\mathrm{i}}=0.54$ predicts $S$ with $\mathrm{R}^{2}$

$430=0.99$. Figure $5 c$ evaluates the empirical model by comparing $S\left(b_{k}, g_{k}, r_{k}, i_{k}\right)$ to $S_{k}$. 
431 Again, there is minimal deviation from the one-to-one line, showing that the linear model

432 well predicts $S$. More complicated variants to Eq. (8) were evaluated, this time including

433 a term equal to the normalized difference vegetation index (NDVI). ${ }^{2}$ The more complex

434 models were found to be no better than the simple linear equation (Eq. (8)). A histogram

435 of residuals is shown in Figure 5d. The linear model can predict $S$ with an RMS error of

$436 \quad 0.016$.

437 The largest outlier is a metal roofing sample (zincalume with clear resin finish) in which

$438 S\left(b_{k}, g_{k}, r_{k}, i_{k}\right)$ underpredicts $S_{k}$ by 0.10 . Figure 4 shows the spectral reflectance of this

439 outlier. It can be seen that the narrowband near-IR spectral range does not capture the

440 increased reflectance at $\lambda>1000 \mathrm{~nm}$; thus, $i(833-920 \mathrm{~nm})$ underpredicts broadband

441 near-IR reflectance $(700-2500 \mathrm{~nm})$. A roofing product with strongly varying spectral

442 reflectance in the near-IR may not always be well characterized by the narrowband near-

443 IR reflectance $i$.

444 3.2. Calibrating remotely sensed values using ground truths

445 Figure 6 shows measured versus remotely sensed (uncalibrated) albedos for the buildings

446 that served as ground truths. Results for the City of Los Angeles and Long Beach are

447 shown together since they are both part of the Greater Los Angeles Area. For low

448 measured albedo ( $S<0.4$ ) most remotely sensed values are near measured values, while

449 for high measured albedo ( $S \geq 0.4$ ), the discrepancy is larger. Remotely sensed albedos

\footnotetext{
${ }^{2}$ NDVI is a metric that is often used to determine whether pixels contain live vegetation, and is calculated as $(I-V) /(I+V)$. Live vegetation characteristically has higher near-IR reflectance than visible reflectance and therefore NDVI > 0 . The use of NDVI in this study was an attempt to identify cool roofs with low reflectance in the visible but high reflectance in the near-infrared. While the metric successfully identified cool colored roofs, adding it as a term to Eq. (8) did not improved the empirical model.
} 
450 are consistently lower than measured values.. To derive remotely sensed (calibrated)

451 albedos, the equations for each city shown in Figure 6 were applied to the uncalibrated

452 values.

453 Table 3 shows an estimate of the error (accuracy) at 90\% confidence interval of the

454 calibrated remotely sensed albedos. Error was calculated using Eqs. (4) and (5). Low

455 albedo values are quite accurate, while high albedo values are generally less accurate.

456 Note that the error for high albedo values is smaller in San Jose than in the other cities

457 because we had a relatively high number $(N=8)$ of high albedo measurements, all of

458 which had consistent remotely sensed values. The reported errors represent the estimated

459 accuracy associated with the mean value for a given roof. However, the relatively large

460 error for high albedo roofs does not markedly influence the mean roof albedo for each

461 city since high albedo roofs comprised a small fraction of total urban roof area in 2009.

462 There may exist individual high albedo roofs that have errors larger than reported (i.e.,

463 outside the $90 \%$ confidence intervals) because of an increased contribution of specular

464 reflectance. These outliers would most commonly have newly installed high albedo roofs

465 with "curvy" roof shapes. The curves in the roof would mean that certain areas have high

466 incidence angles and therefore significant specular reflectance (see Section 2.5 and 4.1).

\section{3.3. Maps of roof albedo}

468 Figure 7 shows a zoomed in area of San Jose with the mean value of calibrated albedo $S^{\prime}$

469 for each roof. As expected in California due to Title-24 Building Energy Efficiency

470 Standards (CEC 2005), some commercial buildings with large flat roofs have high

471 albedo. Homes with pitched roofs usually have low albedo roofs. Our companion paper 
472 (Ban-Weiss et al. submitted) shows city-wide results for all seven cities and provides

473 further analysis.

\section{4. Discussion and Conclusions}

475 4.1. Errors in computed albedo introduced by roof slope.

476 In this study we do not account for the dependence of irradiance on roof slope. This

477 simplification could lead to inaccuracies in remotely sensed albedo since it is the ratio of

478 reflected to incident sunlight. We estimate the magnitude of the error from this

479 simplification using results from Levinson et al. (2010) that quantify the dependence of

480 hemispherical (direct + diffuse) solar irradiance on roof pitch as a function of solar zenith

481 angle (z). In Levinson et al., pitched roofs were approximated by the curved wall of a

482 right circular cone since the population of pitched roof planes have no preferred azimuth

483 orientation. In California, most pitched roofs have slope $\leq 23^{\circ}$ (rise over run $=5: 12$ ),

484 which we used as our pitched roof case for this error estimate.

485 Assuming $\mathrm{z}=0^{\circ}$, hemispherical irradiance $\left(\mathrm{I}_{\mathrm{h}}\right)$ on an axisymmetric surface with a 5:12

486 pitch is $\mathrm{I}_{\mathrm{h}}=1030 \mathrm{~W} \mathrm{~m}^{-2}$, or $5.5 \%$ less than that on a horizontal surface $\left(\mathrm{I}_{\mathrm{h}}=1090 \mathrm{~W} \mathrm{~m}^{-2}\right)$.

487 Assuming $\mathrm{z}=30^{\circ}$, the maximum zenith angle during the flights that acquired the aerial

488 imagery, $\mathrm{I}_{\mathrm{h}}$ is $875 \mathrm{~W} \mathrm{~m}^{-2}$ for a roof pitch of $5: 12$, or $6.4 \%$ less than that on a horizontal

489 surface $\left(\mathrm{I}_{\mathrm{h}}=935 \mathrm{~W} \mathrm{~m}^{-2}\right)$. Therefore, for $\mathrm{z} \leq 30^{\circ}$ we may have overestimated solar

490 irradiance by up to about $6 \%$, leading to underestimates for albedo of about $6 \%$.

\section{4.2. Precision error}

492 The errors introduced by simplifications in viewing geometry (Section 2.2) and roof pitch

493 (Section 4.1) used in this study can be explored by comparing the computed albedos 
494 derived for buildings with overlapping imagery and therefore two remotely sensed values

495 (see Section 2.7). Regions with duplicate albedos are generally at flight strip edges with

496 corresponding view zenith angles of (a) $\square 34^{\circ}$ to $\square 30^{\circ}$, and (b) $+30^{\circ}$ to $+34^{\circ}$. Solar zenith

497 angles also generally vary for each of the duplicate values, though there is no consistent

498 difference among flight strips. If the aforementioned simplifications introduced

499 appreciable error, one would expect the duplicate remotely sensed albedos for a given

500 building to be markedly different. The full precision analysis is presented in the

501 companion paper (Ban-Weiss et al. submitted), but as an example result for one of the

502 cities investigated here, the 430,332 buildings in Los Angeles with independently

503 computed duplicate albedos showed an RMS scaled arithmetic difference (Eq. 6) of 0.02,

504 suggesting the simplifications discussed here lead to small errors for most roofs.

511 reflectance in the visible but high reflectance in the near-IR, and (2) about $50 \%$ of the

512 energy from the sun is in the near-IR part of the solar spectrum. We have developed

513 methods for (a) identifying building outlines (Table 1, Figure 3), (b) converting the four

514 narrowband reflectances to solar reflectance (albedo) based on laboratory measurements

515 of solar spectral reflectance for 190 roofing products (Table 2, Figure 4, Figure 5), and

516 (c) calibrating remotely sensed albedos by comparing to measured albedos of several 
517 roofs in each city (Figure 6). We have found our method to be quite accurate for most

518 roof types in California, while errors in computed albedos are relatively large for high

519 albedo roofs that are presumably new and white (see Table 3). For example, roofs with an

520 albedo near 0.2 had estimated errors (one-sided, $90 \%$ confidence intervals) ranging from

5210 to 0.02 , varying by city. On the other hand, roofs with an albedo near 0.8 had

522 corresponding errors ranging from 0.05 to 0.12 . The method was also shown to be

523 precise. Precision error, computed using duplicate albedo values for roofs in flight

524 overlap areas, was found to be 0.02 for Los Angeles (see Section 4.2). Each duplicate

525 albedo was derived using remotely sensed data with differing viewing and illumination

526 geometries.

527 In our companion paper (Ban-Weiss et al. submitted), we present city-wide albedo results

528 for our seven California cities of interest, report results of the precision analysis for all

529 analyzed cities, and provide additional analyses based on the city-wide results. We also

530 use the roof albedo results for Bakersfield as an input to a regional climate model to

531 predict the summer and winter temperature and precipitation changes that could result

532 from converting the current stock of roofs to cool roofs.

\section{5. Acknowledgements}

534 The authors thank Ash Lashgari, Eileen McCauley, and Tony VanCuren of the California

535 Air Resources Board; Doug Cain of North West Group; Sharon Chen, Pablo Rosado, Ben

536 Mandel, and Ling Jin of Lawrence Berkeley National Laboratory; and Ana Paula Werle

537 of Universidade de São Paulo. For rooftop access we thank John Skyberg and

538 Christopher Brown of San Jose State University; Leroy Sisneros and Fran Knight of

539 University of California, Los Angeles; Chet Galland of California State University, 
540 Northridge; Craig Meyer of Pierce College; Victor Lai and Charles A. Meyer of San

541 Francisco State University; and John Zertuche, Cynthia Kranc, and Jon Wildberger of

542 University of California, Davis. For roof installation data we thank CertainTeed; Joe

543 Mellott, Tom Chapman, Amy Digby, and Sean Gavin of The Garland Company, Inc;

544 Michael Kearney of GAF; Tony Zaffuto of Sylvester Roofing Co. Inc.; and Emmie

545 Limon of SureCoat Systems. This project was funded by the California Air Resources

546 Board under Contract 10-321. It was also supported by the Assistant Secretary for Energy

547 Efficiency and Renewable Energy, Office of Building Technology, State, and

548 Community Programs, of the U.S. Department of Energy under Contract No. DE-AC02-

549 05CH11231. The statements and conclusions in this paper are those of the authors and

550 not necessarily those of the California Air Resources Board. 


\section{References}

Akbari H, Rosenfeld A, Taha H (1990). Summer heat islands, urban trees, and white surfaces. In Proceedings of the 1990 ASHRAE Winter Conference. http://isswprod.lbl.gov/library/view-docs/public/output/LBL-28308.pdf.

Akbari H, Davis S, Dorsano S, Huang J (1992). Cooling Our Communities: A Guidebook on Tree Planting and Light-Colored Surfacing. A Report to the United States

Environmental Protection Agency. Report number 22P.2001.

http://escholarship.org/uc/item/98z8p10x.

Akbari H, Bretz S, Taha H, Kurn D, Hanford J (1997). Peak power and cooling energy savings of high-albedo roofs. Energy and Buildings, 25, 117-126.

Akbari H, Rose LS, Taha H (1999). Characterizing the Fabric of the Urban Environment: A Case Study of Sacramento, California. Lawrence Berkeley National Laboratory Report LBNL-44688, Berkeley, CA. doi:10.2172/764362.

Akbari H, Pomerantz M, Taha H (2001). Cool surfaces and shade trees to reduce energy use and improve air quality in urban areas. Solar Energy, 70, 295-310.

Akbari H, Rose LS (2001a). Characterizing the fabric of the urban environment: a case study of metropolitan Chicago, Illinois. Lawrence Berkeley National Laboratory Report LBNL-49275, Berkeley, CA. http://repositories.cdlib.org/lbnl/LBNL-49275.

Akbari H, Rose LS (2001b). Characterizing the fabric of the urban environment: a case study of Salt Lake City, Utah. Lawrence Berkeley National Laboratory Report LBNL47851, Berkeley, CA. http://escholarship.org/uc/item/0wk718sm.

Akbari H, Rose LS, Taha H (2003). Analyzing the land cover of an urban environment using high-resolution orthophotos. Landscape and Urban Planning, 63, 1-14.

Akbari H (2003). Measured energy savings from the application of reflective roofs in two small non-residential buildings. Energy, 28, 953-967.

Akbari H, Levinson R, Rainer L (2005). Monitoring the energy-use effects of cool roofs on California commercial buildings. Energy and Buildings, 37, 1007-1016.

Akbari H, Rose LS (2008). Urban Surfaces and Heat Island Mitigation Potentials. Journal of the Human-Environmental System, 11, 85-101.

Akbari H, Menon S, Rosenfeld A. (2009) Global cooling: Increasing world-wide urban albedos to offset CO2. Climatic Change, 94, 275-286.

Akbari H, Matthews HD (2012). Global cooling updates: Reflective roofs and pavements. Energy and Buildings, 55, 2-6, doi: 10.1016/j.enbuild.2012.02.055. 
Akbari H, Matthews HD, Seto D (2012). The long-term effect of increasing the albedo of urban areas. Environmental Research Letters, 7, 1-10.

ASTM (2006) ASTM Standard E1918-06, Standard Test Method for Measuring the Solar Reflectance of Horizontal and Low-Sloped Surfaces in the Field, ASTM International, West Conshohocken, PA.

Ban-Weiss GA, Woods J, Millstein D, Levinson R (submitted). Using remote sensing to quantify albedo of roofs in California's seven largest cities, Part 2: Results and application to climate modeling. (Submitted to Solar Energy as a companion paper)

Ban-Weiss GA, Wray C, Delp W, Ly P, Akbari H, Levinson R (2013). Electricity production and cooling energy savings from installation of a building-integrated photovoltaic roof on an office building. Energy and Buildings, 56, 210-220.

Beisl U, Telaar J, Schönermark MV (2008). Atmospheric correction, reflectance calibration and BRDF correction for ADS40 image data. The International Archives of the Photogrammetry, Remote Sensing and Spatial Information Sciences, Vol. XXXVII, Part B7, http://isprsserv.ifp.uni-stuttgart.de/proceedings/XXXVII/congress/7_pdf/1_WGVII-1/02.pdf .

Beisl U, Adiguezel M (2010). Validation of the reflectance calibration of the ADS40 airborne sensor using ground reflectance measurements. ISPRS TC VII Symposium - 100 Years ISPRS, Vienna, Austria, July 5-7, 2010, IAPRS, Vol. XXXVIII, Part 7B, http://www.isprs.org/proceedings/XXXVIII/part7/b/pdf/80_XXXVIII-part7B.pdf .

Campra P, Garcia M, Canton Y and Palacios-Orueta A (2008). Surface temperature cooling trends and negative radiative forcing due to land use change toward greenhouse farming in southeastern Spain. Journal of Geophysical Research, 113, D18109. doi:10.1029/2008JD009912.

CEC (2005). California Energy Commission Building Energy Efficiency Standards, For Residential and Nonresidential. Publication \# CEC-400-2006-015 http://www.energy.ca.gov/2006publications/CEC-400-2006-015/CEC-400-2006015.PDF.

City and County of San Francisco (2011). San Francisco Data. Building Footprints. Obtained in 2011 at https://data.sfgov.org/.

City of Bakersfield (2011). Geographic Information Services. Obtained in 2011 at http://www.bakersfieldcity.us/gis/downloads/.

City of San Jose (2011). GIS/Public Works. Building outlines for 2006. Obtained in 2011 by personal communication with Vicky Gallardo, Senior Geosystems Specialist.

Cotana F, Rossi F, Filipponi M, Coccia V, Pisello AL, Bonamente E, Petrozzi A, Cavalaglio G (2014) Albedo control as an effective strategy to tackle Global Warming: A case study. Applied Energy, 130, 641=647, doi:10.1016/j.apenergy.2014.02.065. 
CRRC (2013). Cool Roof Rating Council Rated Products Directory, http://coolroofs.org.

Downey M, Uebbing R, Gehrke S, Beisl U (2010). Radiometric processing of ADS imagery: using atmospheric and BRDF corrections in products. ASPRS 2010 Annual Conference, San Diego, CA.

http://www.asprs.org/a/publications/proceedings/sandiego2010/sandiego10/Downey.pdf.

Fraser RS, Ferrare RA, Kaufman YJ, Markham B L, and Mattoo S (1992). Algorithm for atmospheric corrections of aircraft and satellite imagery. Int. J. Remote Sensing, 13, 541557.

Georgescu M, Mahalov A, Moustaoui M (2012). Seasonal hydroclimatic impacts of Sun Corridor expansion. Environmental Research Letters, 7, 1-9.

Hyslop NP, White WH (2009). Estimating precision using duplicate measurements, Journal of the Air and Waste Management Association, 59, 1032-1039.

doi:10.3155/1047-3289.59.9.1032

Jacobson MZ, Ten Hoeve JE (2012). Effects of urban surfaces and white roofs on global and regional climate. Journal of Climate, 25, 1028-1044.

Kaufman JY and Sendra C (1988). Algorithm for automatic atmospheric corrections to visible and near-IR satellite imagery, Int. J. Remote Sensing, 9, 1357 - 1381.

Konopacki S, Akbari H (2001). Measured energy savings and demand reduction from a reflective roof membrane on a large retail store in Austin. Lawrence Berkeley National Laboratory Report LBNL-47149, Berkeley, CA. doi:10.2172/787107.

Leica (2013). Leica ADS80 Airborne Digital Sensor Digital Airborne Imaging Solution. http://www.leica-geosystems.com/downloads123/zz/airborne/ads80/brochuresdatasheet/ADS80_datasheet_en.pdf.

Levinson R, Akbari H (2010). Potential benefits of cool roofs on commercial buildings: conserving energy, saving money, and reducing emission of greenhouse gases and air pollutants. Energy Efficiency, 3, 53-109.

Levinson R, Akbari H, Berdahl P (2010). Measuring solar reflectance-Part I: Defining a metric that accurately predicts solar heat gain. Solar Energy, 84, 1717-1744.

Levinson R, Berdahl P, Abkari H, Miller W, Joedicke I, Reilly J, Suzuki Y, Vondran M (2007). Methods of creating solar-reflective nonwhite surfaces and their application to residential roofing materials. Solar Energy Materials \& Solar Cells, 91, 304-314.

Los Angeles Region Imagery Acquisition Consortium 3 (2011). LAR-IAC3, http://planning.lacounty.gov/LARIAC/lariac3Main.htm.

Lynn BH, Carlson TN, Rosenzweig C, Goldberg R, Druyan L, Cox J, Gaffin S, Parshall L, Civerolo K (2009). A modification to the NOAH LSM to simulate heat mitigation 
strategies in the New York City metropolitan area. Journal of Applied Meteorology and Climatology, 48, 199-216.

Markelin L, Honkavaara E, Beisl U, Korpela I (2010). Validation of the radiometric processing chain of the LEICA ADS40 airborne photogrammetric sensor. ISPRS TC VII Symposium - 100 Years ISPRS, Vienna, Austria, July 5-7, 2010, IAPRS, Vol. XXXVIII, Part 7A. http://www.isprs.org/proceedings/XXXVIII/part7/a/pdf/145_XXXVIIIpart7A.pdf.

Menon S, Akbari H, Mahanama S, Sednev I, Levinson R (2010). Radiative forcing and temperature response to changes in urban albedos and associated $\mathrm{CO}_{2}$ offsets. Environmental Research Letters, 5, 1-11.

Millstein D, Menon S (2011). Regional climate consequences of large-scale cool roof and photovoltaic array deployment. Environmental Research Letters, 6, 1-9.

NAIP (2013). National Agriculture Imagery Program, United States Department of Agriculture's Farm Service Agency (FSA).

http://www.fsa.usda.gov/FSA/apfoapp?area=home\&subject=prog\&topic=nai.

Nilson T, Kuusk A (1989). A reflectance model for the homogeneous plant canopy and its inversion. Remote Sensing of Environment, 27, 157-167.

Oleson KW, Bonan GB, Feddema J (2010). Effects of white roofs on urban temperature in a global climate model. Geophysical Research Letters, 37.

doi:10.1029/2009GL042194.

Parker DS, Barkaszi Jr. SF, Chandra S, Beal DJ (1995). Measured cooling energy savings from reflective roofing systems in Florida: field and laboratory research results. In Proceedings of the Thermal Performance of the Exterior Envelopes of Buildings VI, Clearwater, FL, December 4-8.

Parker DS, Sherwin JR, Sonne JK (1998). Measured performance of reflective roofing systems in a Florida commercial building. In American Society of Heating, Refrigeration, and Air Conditioning Engineers, Atlanta, Georgia, January, ASHRAE Transactions, 104, 1.

Rose LS, Akbari H, Taha H (2003). Characterizing the fabric of the urban environment: a case study of greater Houston, Texas. Lawrence Berkeley National Laboratory Report LBNL-51448, Berkeley, CA, http://repositories.cdlib.org/lbnl/LBNL-51448.

Rosenfeld A, Akbari H, Bretz S, Fishman B, Kurn D, Sailor D, Taha H (1995). Mitigation of urban heat islands: materials, utility programs, updates. Energy \& Buildings, 22, 255-265.

Schaaf CB, Gao F, Strahler AH, Lucht W, Li XW, Tsang T et al. (2002). First operational BRDF, albedo nadir reflectance products from MODIS. Remote Sensing of Environment, 83, 135-148. 
Schaaf CB (2004). MODIS BRDF/Albedo Product (MOD43B) User's Guide, http://www-modis.bu.edu/brdf/userguide/albedo.html. See also http://modisatmos.gsfc.nasa.gov/ALBEDO/.Slaton MR, Hunt Jr ER, Smith WK (2001). Estimating near-infrared leaf reflectance from leaf structural characteristics. American Journal of Botany, 88, 278-284.

Schaepman-Strub G, Schaepman ME, Painter TH, Dangel S, Martonchik JV (2006) Reflectance quantities in optical remote sensing - definitions and case studies. Remote Sensing of Environment, 103, 27-42.

Sleiman M, Ban-Weiss GA, Gilbert H, Francois D, Berdahl P, Kirchstetter T, Destaillats H, Levinson R (2011). Soiling of building envelope surfaces and its effect on solar reflectance-part I: analysis of roofing product databases. Solar Energy Materials and Solar Cells, 95, 3385-3399.

Song J, Lu D, and Weseley M L (2003). A simplified atmospheric correction procedure for the normalized difference vegetation index. Photogramm. Eng. Remote Sens., 69, 521-528.

Synnefa A, Dandou A, Santamouris M, Tombrou M, Soulakellis N (2008). On the use of cool materials as a heat island mitigation strategy. Journal of Applied Meteorology and Climatology, 47, 2846-56.

Taha H, Akbari H, Rosenfeld A, Huang J (1988). Residential cooling loads and the urban heat island-the effects of albedo. Building and Environment, 23, 271-283.

Taha H (2008a). Urban surface modification as a potential ozone air-quality improvement strategy in California: a mesoscale modelling study. Boundary Layer Meteorology, 127, 219-39.

Taha H (2008b). Meso-urban meteorological and photochemical modeling of heat island mitigation. Atmospheric Environment, 42, 8795-8809.

Taha H (2008c). Episodic performance and sensitivity of the urbanized MM5 (uMM5) to perturbations in surface properties in Houston Texas. Boundary Layer Meteorology, 127 193-218.

Wanner W, Li X, Strahler AH (1995). On the derivation of kernels for kernel-driven models of bidirectional reflectance. Journal of Geophysical Research, 100, 21077-21089.

Zhou Y, Shepherd JM (2009). Atlanta's urban heat island under extreme heat conditions and potential mitigation strategies. Natural Hazards, 52, 639-668. 
Table 1. Sources of shapefiles containing outlines of all buildings within five of the seven cities of focus. Outlines were not available in Sacramento and San Diego.

\begin{tabular}{|l|l|}
\hline City & Source \\
\hline San Jose & City of San Jose (2011) \\
\hline San Francisco & City and County of San Francisco (2011) \\
\hline Bakersfield & City of Bakersfield (2011) \\
\hline $\begin{array}{l}\text { City of } \\
\text { Los Angeles }\end{array}$ & Los Angeles Region Imagery Acquisition Consortium 3 (2011) \\
\hline Long Beach & Los Angeles Region Imagery Acquisition Consortium 3 (2011) \\
\hline
\end{tabular}


Table 2. Roofing samples for which we measured solar spectral reflectances in the laboratory.

\begin{tabular}{|l|l|}
\hline Roofing product type & Number of samples \\
\hline Asphalt shingle & 75 \\
\hline Concrete tile & 25 \\
\hline Clay tile & 36 \\
\hline Metal roofing & 5 \\
\hline Single-ply membrane & 30 \\
\hline $\begin{array}{l}\text { Modified bitumen cap } \\
\text { sheet }\end{array}$ & 14 \\
\hline Field-applied coating & 5 \\
\hline & \\
\hline Total & $\mathbf{1 9 0}$ \\
\hline
\end{tabular}




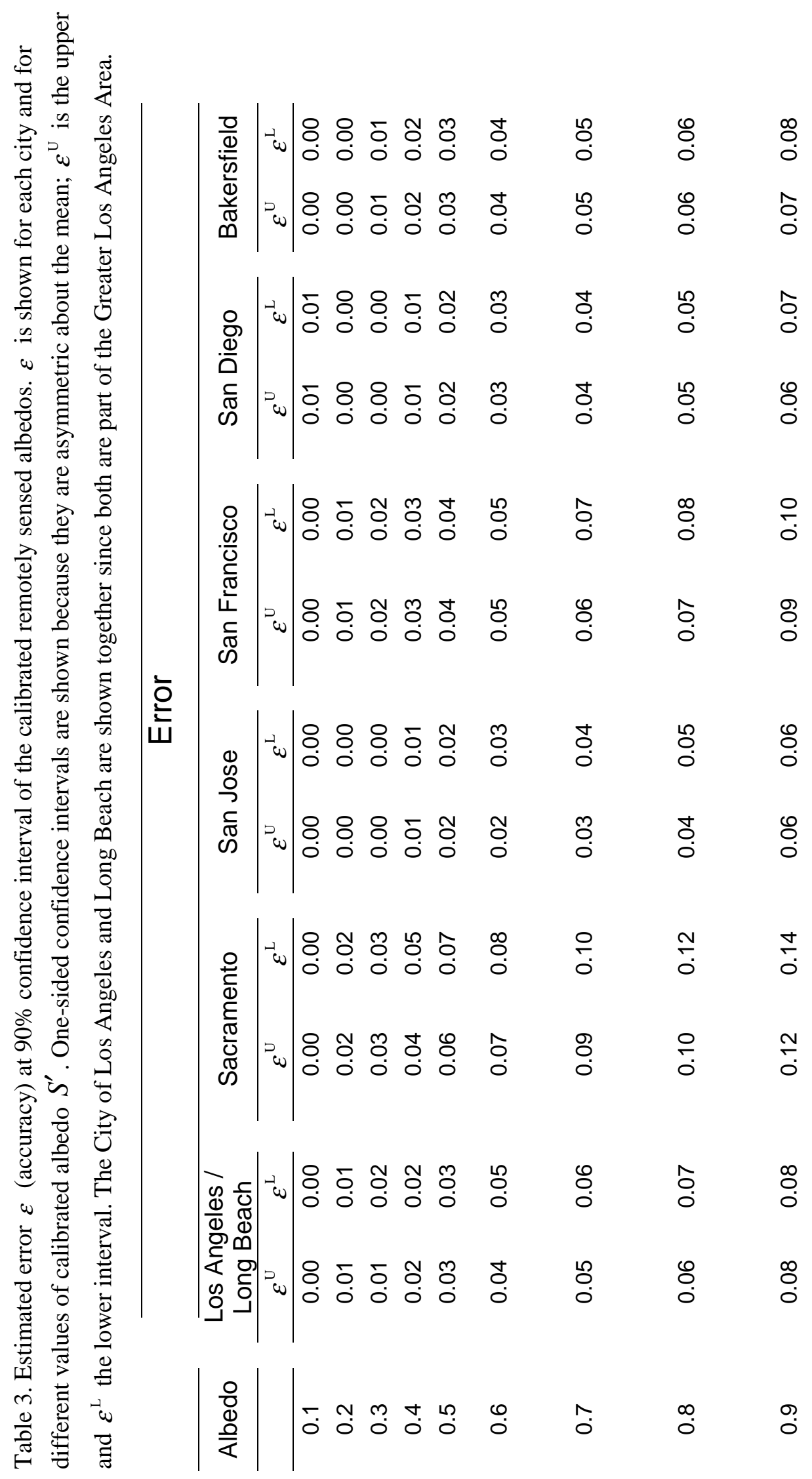



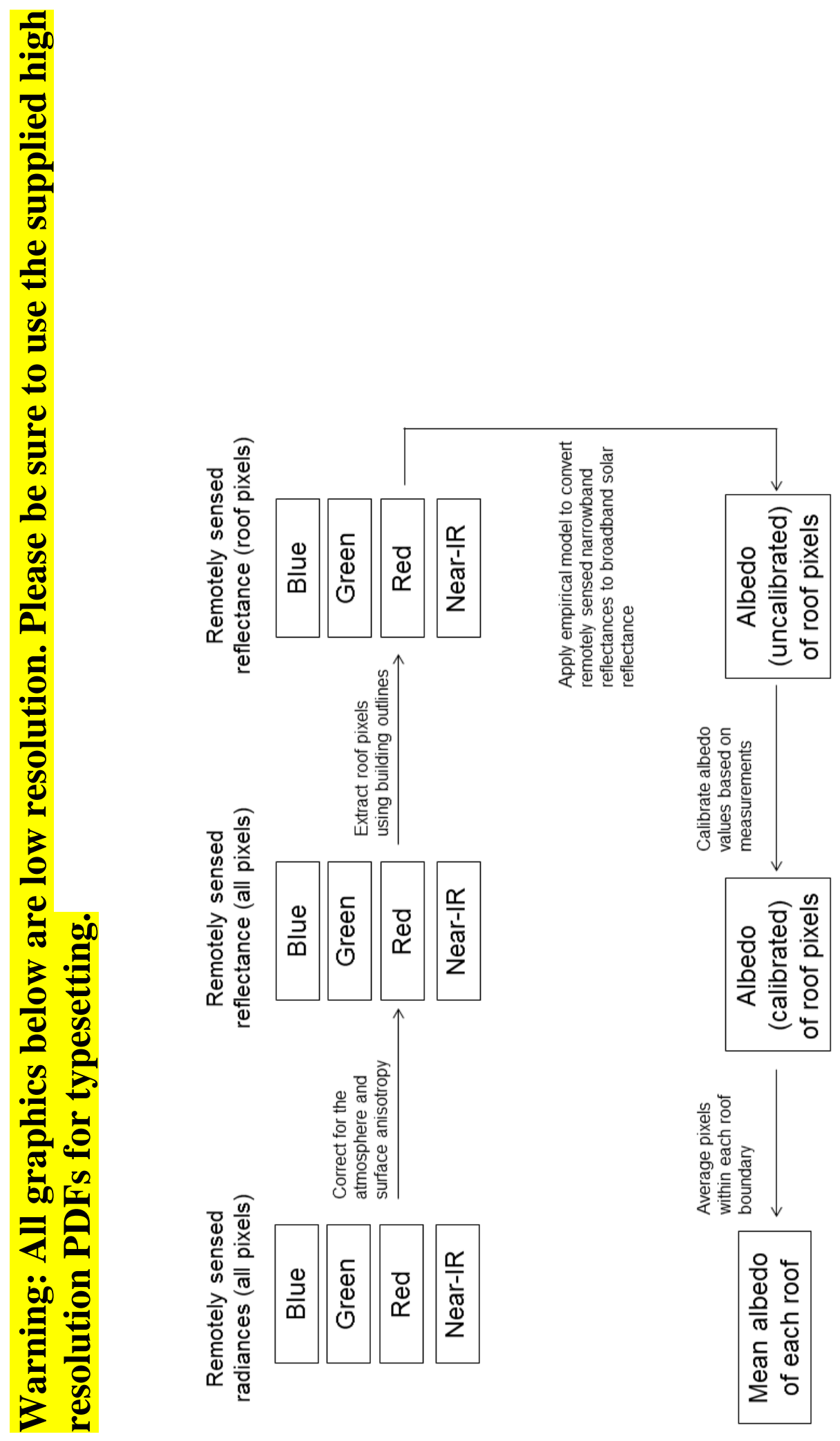

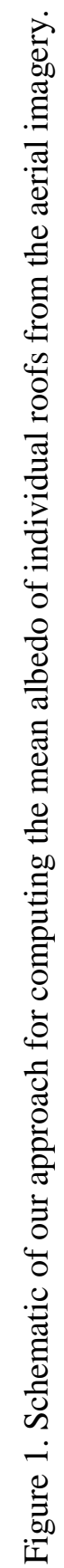


a.

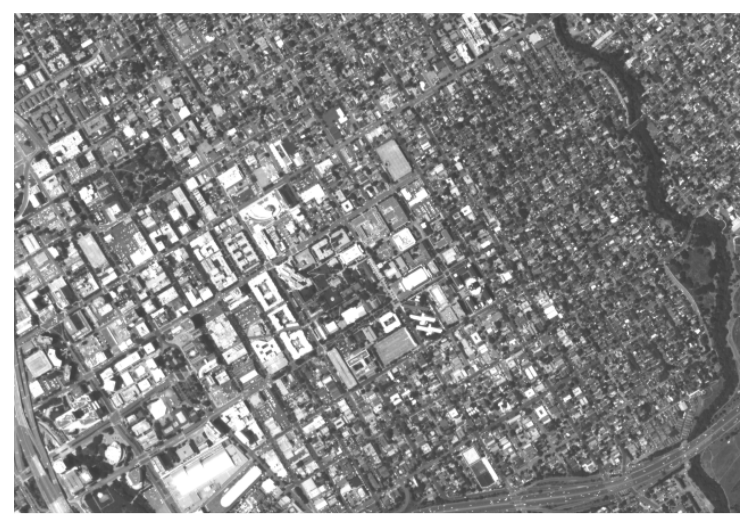

c.

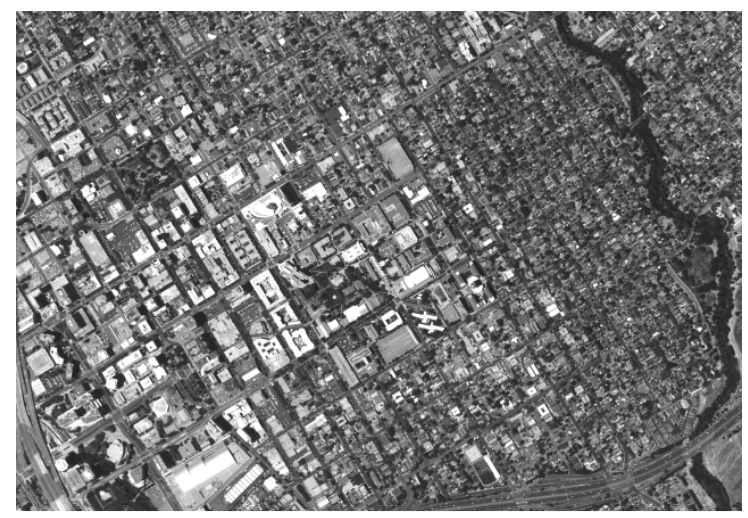

b.

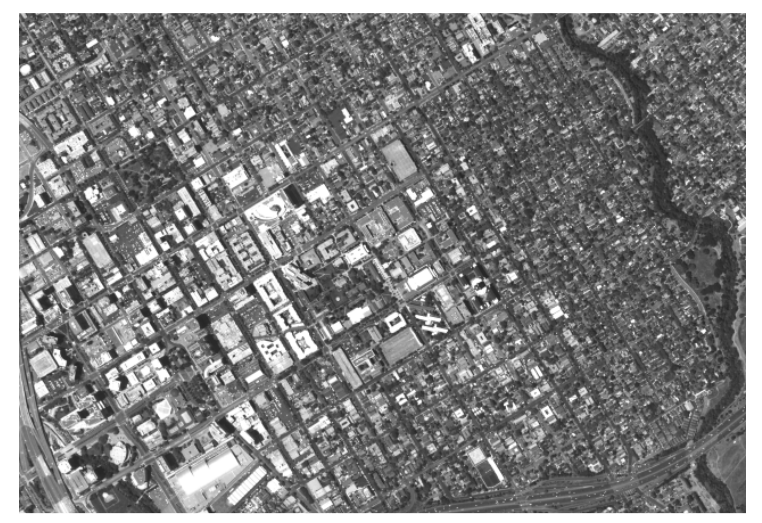

d.

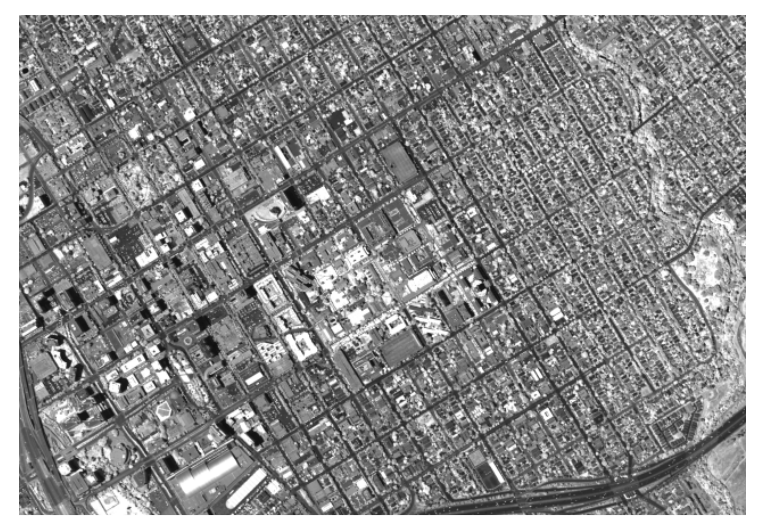

Figure 2. Examples of the $1 \mathrm{~m}$ resolution remotely sensed imagery for a portion of San Jose, California, showing reflectance in four narrow bands: (a) blue $(420-492 \mathrm{~nm})$, (b) green $(533-$ $587 \mathrm{~nm}),(\mathrm{c})$ red $(604-664 \mathrm{~nm})$, and (d) near-IR $(833-920 \mathrm{~nm})$. 
a

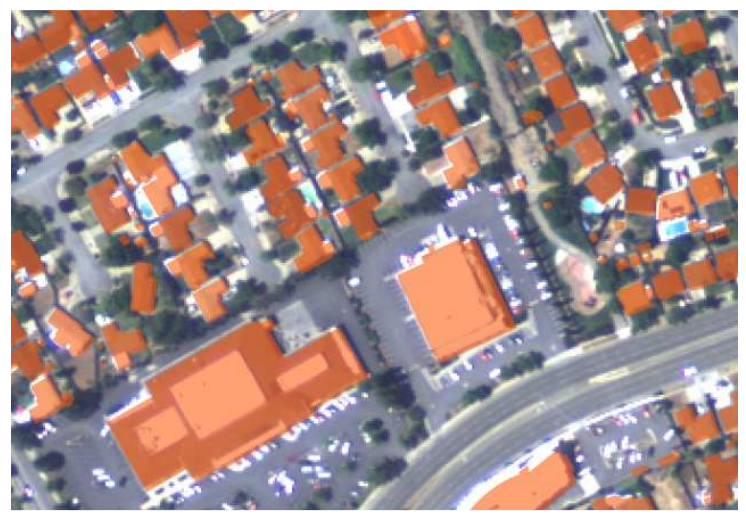

b

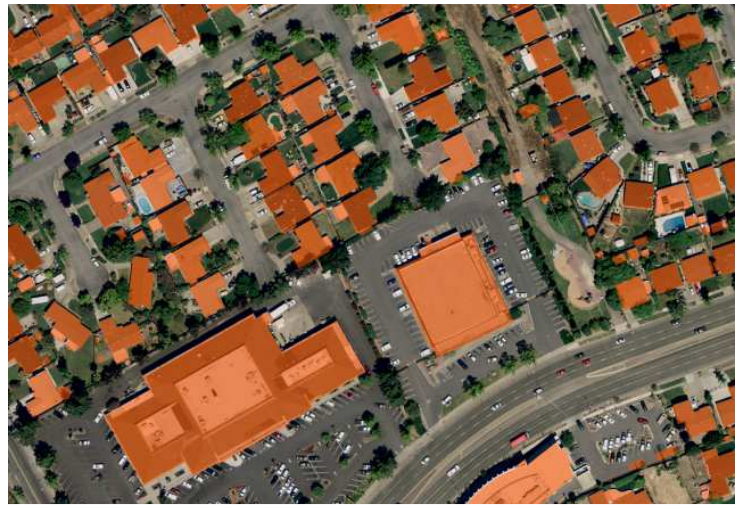

c

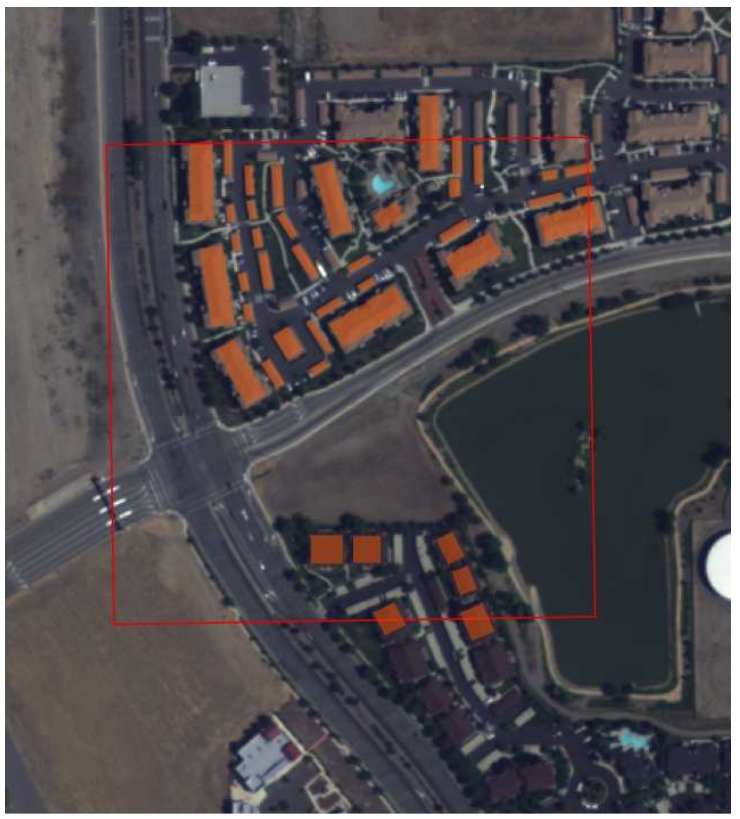

Figure 3. Example building outlines. Outlines provided by the City of San Jose are shown in (a) and (b). Manually traced outlines in Sacramento are in (c). In (a) and (c) the underlying imagery is an RGB composite of the aerial imagery described in this paper. Panel b uses higher-resolution (but not radiometrically calibrated) background imagery from the United States Geological Survey) to better resolve fine features. 


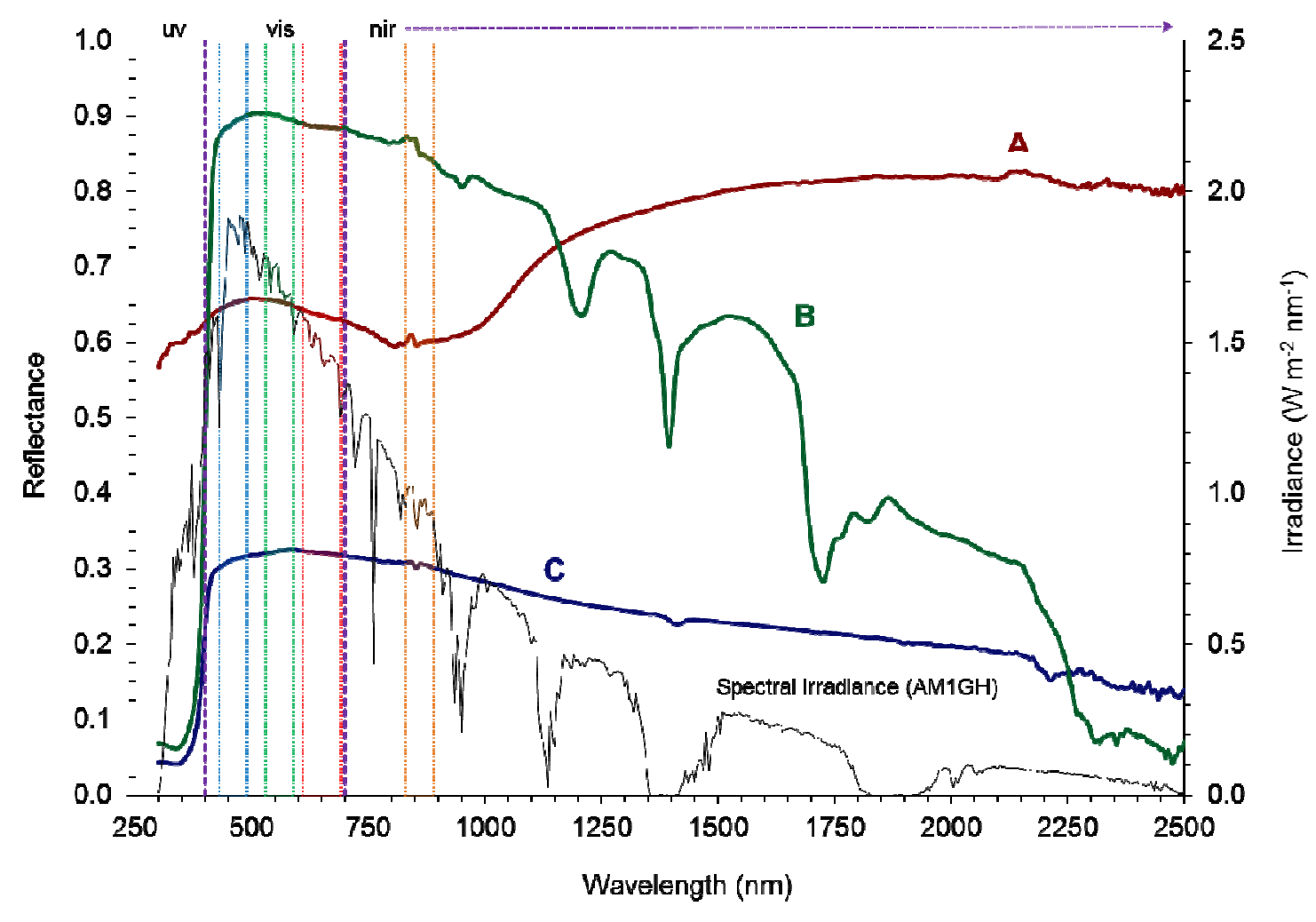

A. Metal roof

B. White membrane

C. Cap sheet
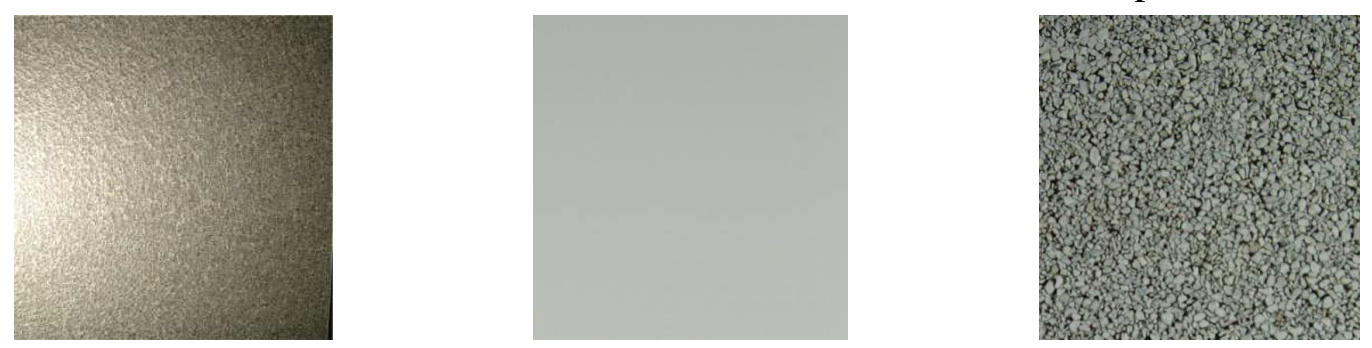

Figure 4. Solar spectral reflectances of three roofing products: (A) metal (zincalume with clear resin), (B) white membrane, and (C) granule-surfaced modified bitumen cap sheet. Also shown is the solar spectral global horizontal irradiance at Earth's surface (black line) assuming clear sky with the sun at zenith, referred to as Air Mass 1 Global Horizontal (AM1GH). Narrowband spectral ranges (blue, green, red, near-IR) for the airborne digital sensor (ADS80/SH82) used to collect the imagery are shaded. 


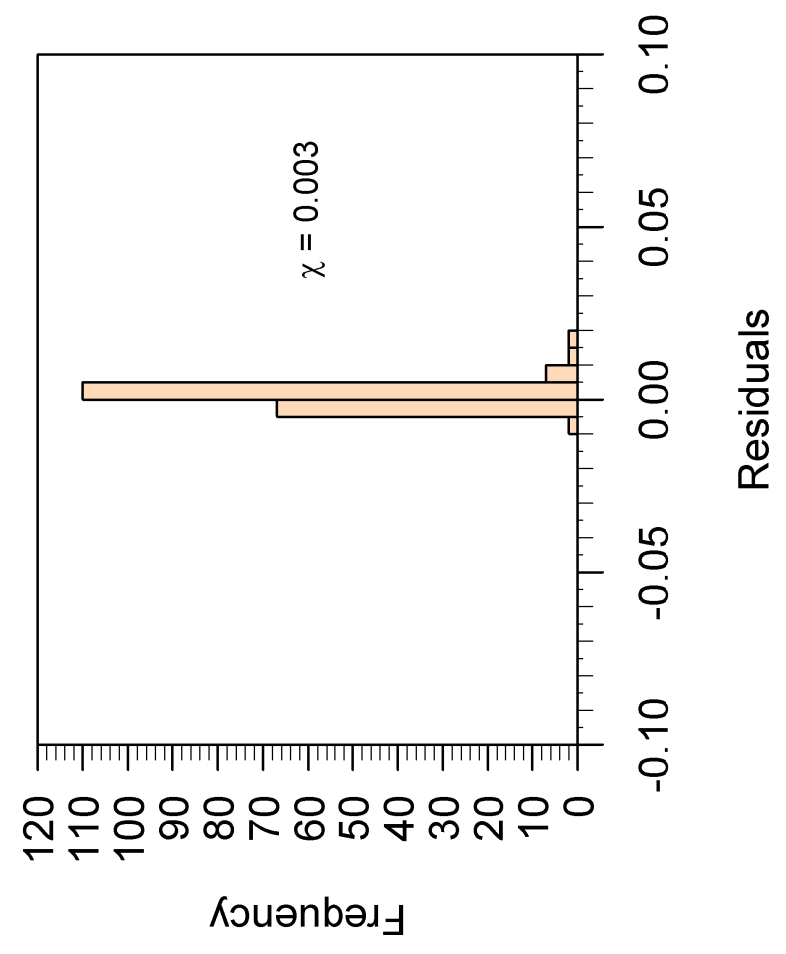

ம
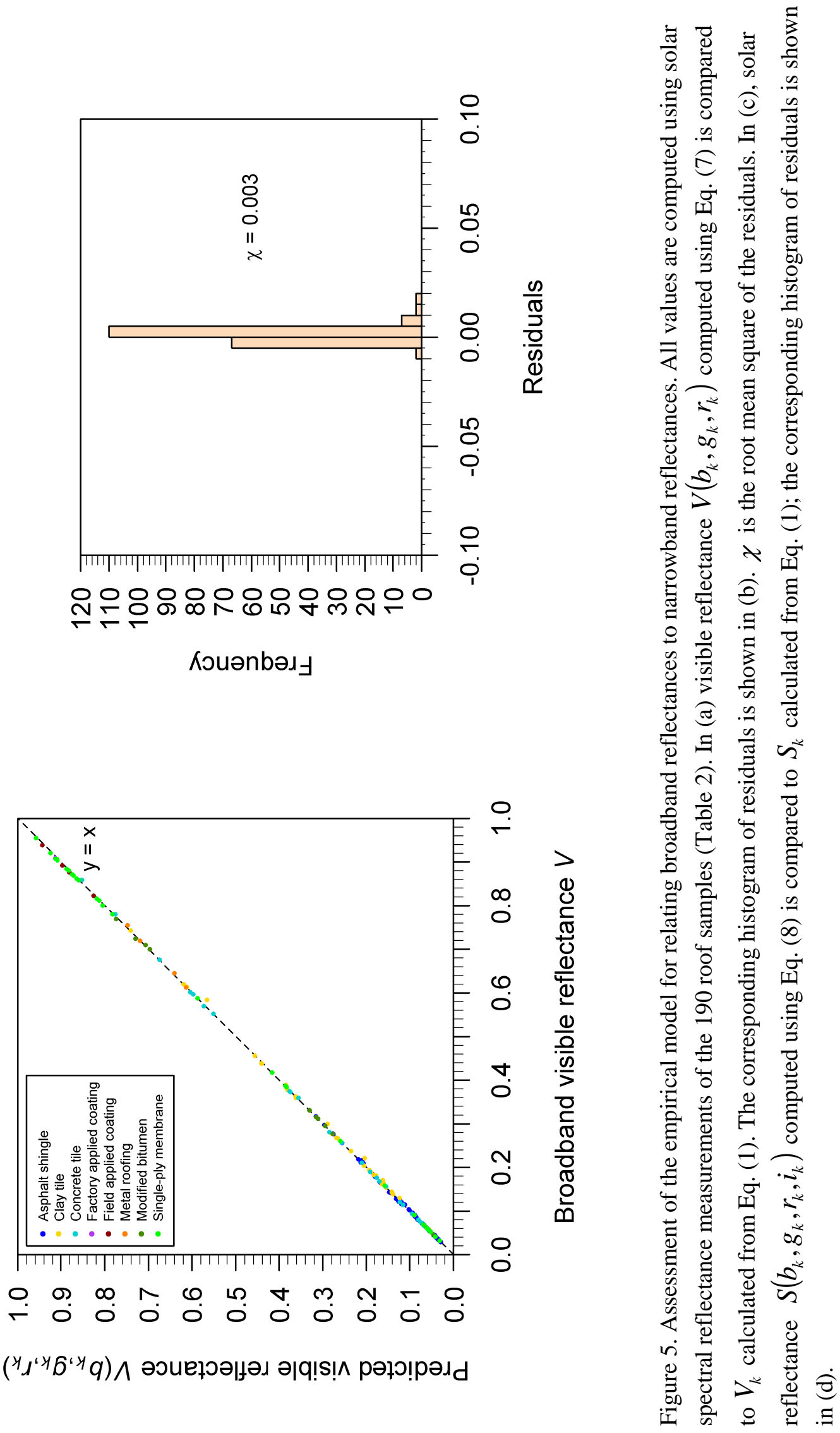


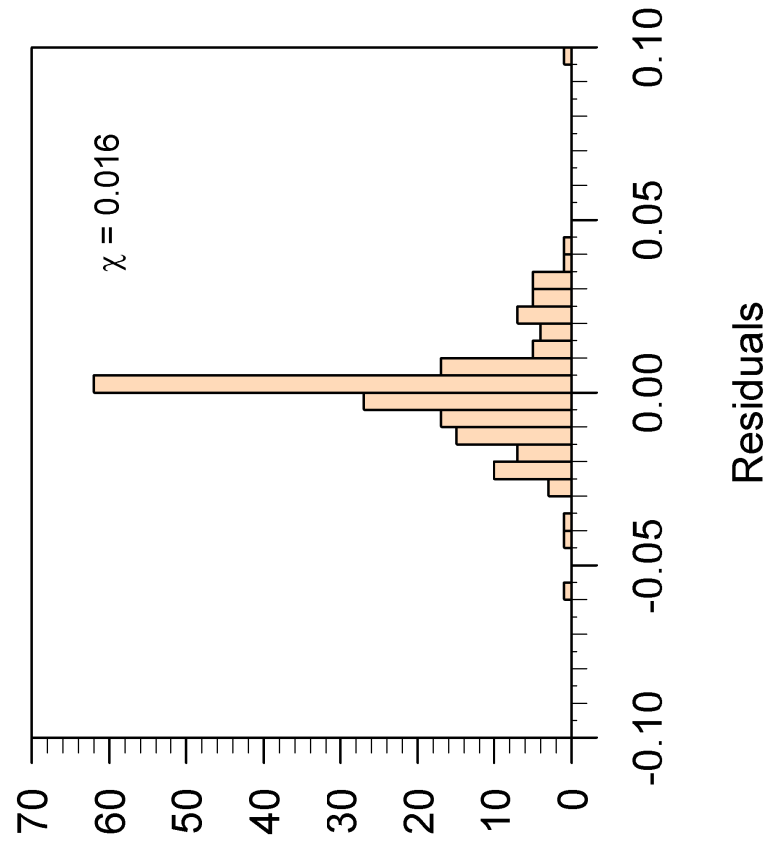

ヘวuənbəィ」

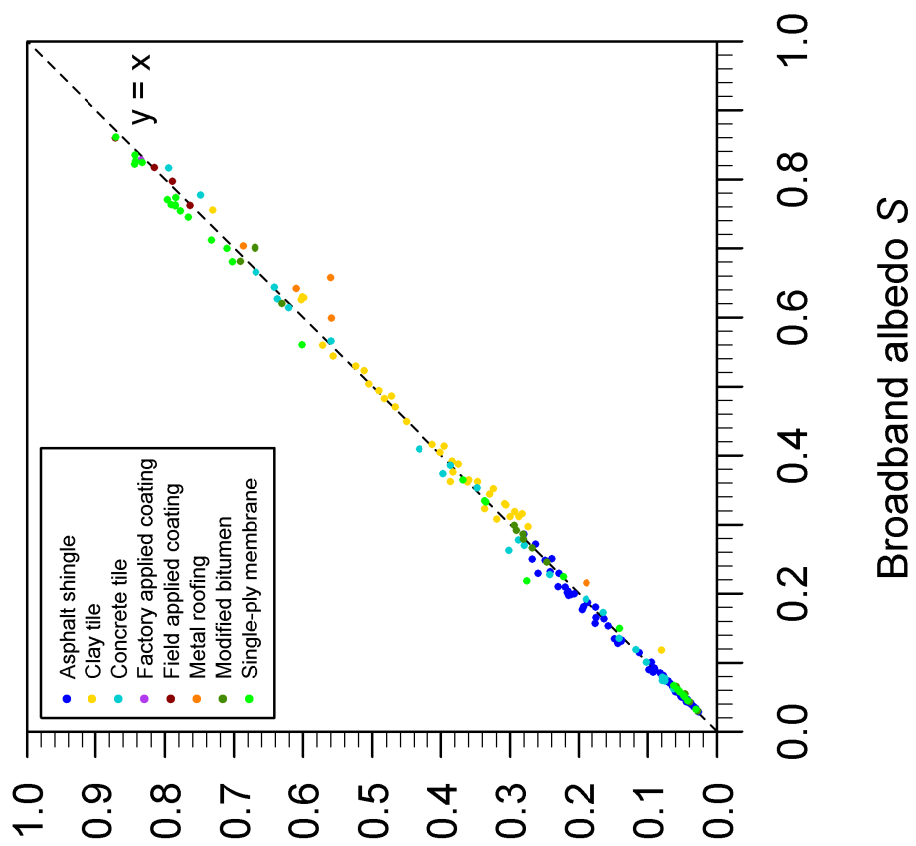

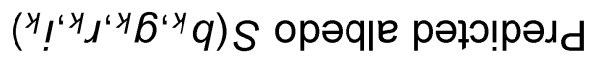




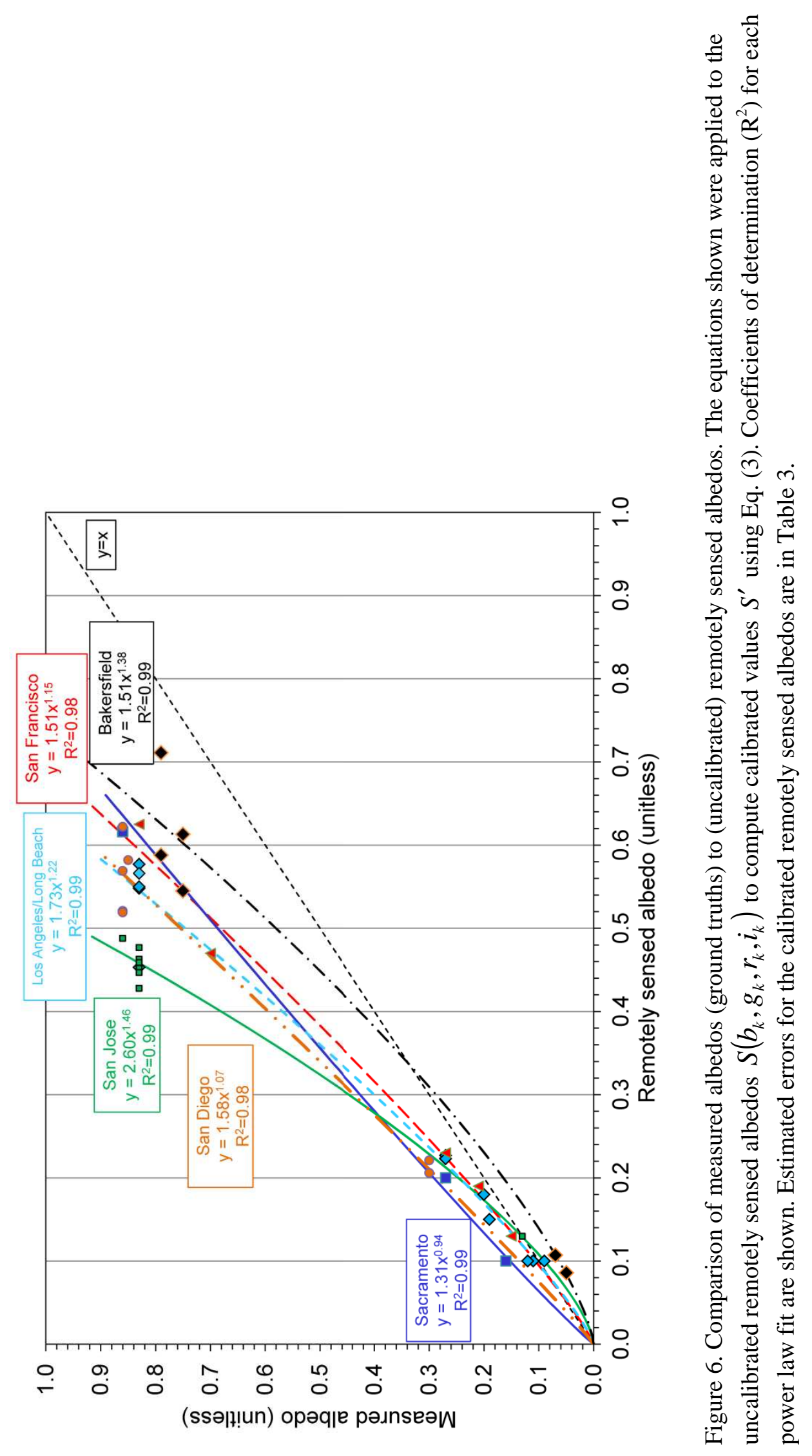




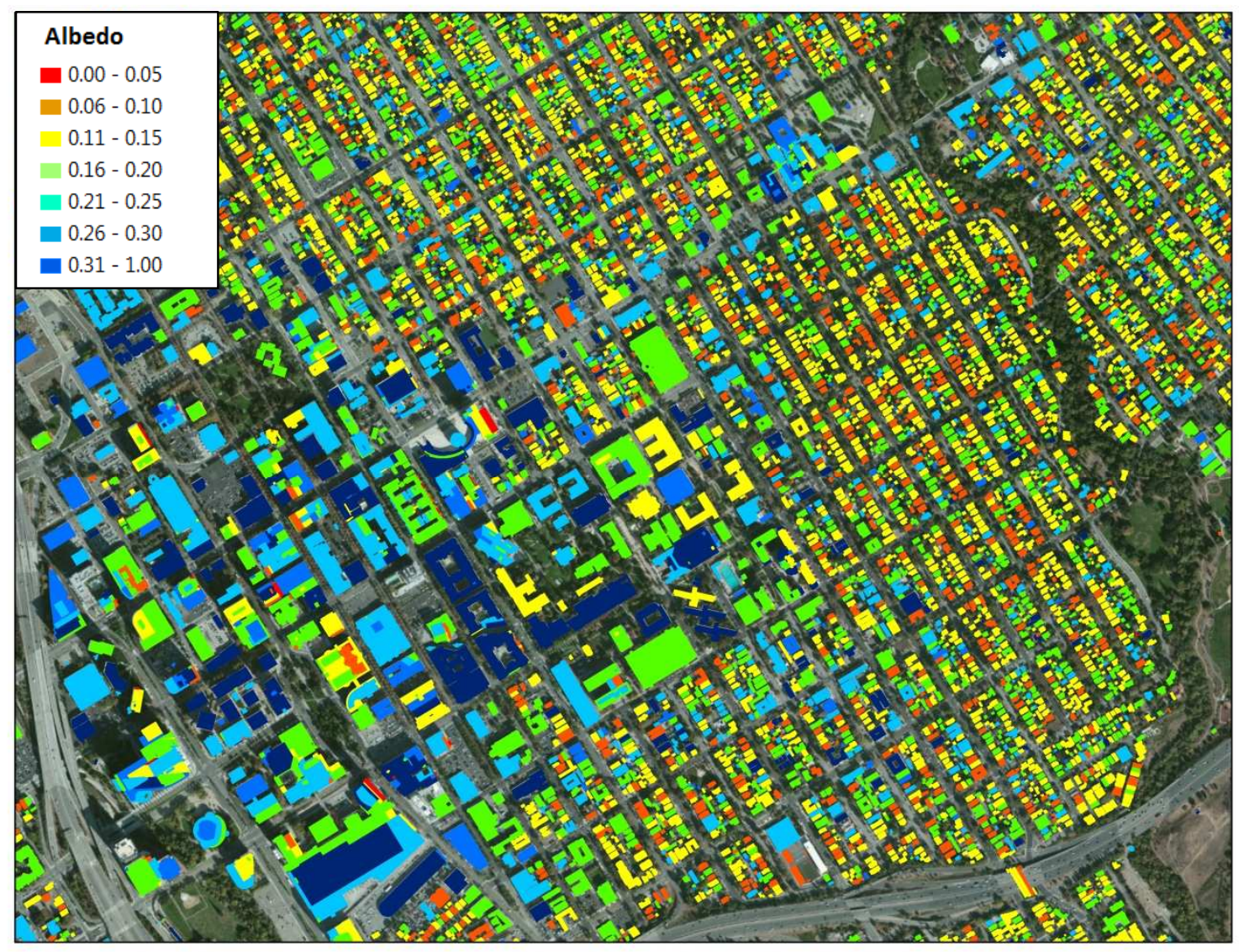

Figure 7. A portion of San Jose showing the mean (calibrated) remotely sensed albedo for each rooftop. Albedos correspond to estimated bihemispherical solar reflectance. 